\title{
Validation of End Effector Matrix for Robotic Kit OWI-535 using MATLAB and Robo Analyzer
}

\author{
Bhivraj Suthar*, Tanmay Shrivastava**, Lamyanba Heisnam*** \\ *Department of Mechanical Engineering, Indian Institute of Technology Delhi, India \\ **Department of Mechanical Engineering, Shri Govindram Seksariya Institute of Science and Technology, Indore \\ ***Department of Mechanical Engineering, National Institute of Technology Hamirpur
}

\begin{tabular}{l} 
Article Info \\
\hline Article history: \\
Received Nov 9, 2015 \\
Revised Jan 26, 2016 \\
Accepted Feb 13, 2016 \\
\hline Keyword: \\
Educational Robotic Kit OWI \\
535 \\
MATLAB \\
Robo Analyzer Software
\end{tabular}

Corresponding Author:

Bhivraj Suthar,

Departement of Mechanical Engineering,

Indian Institute of Technology Delhi, India

Email: bhivraj.iitd@gmail.com

\begin{abstract}
This paper presents the validation of the end effector matrix having D-H parameter of the 4 DOF educational manipulator OWI- 535 by MATLAB and Robo Analyzer. Transformation matrix of order $4 \times 4$ which describes end effecter's position and orientation with respect to the base reference frame. MATLAB programming which gives details about the translation steps of the manipulator simultaneously. Forward kinematics of OWI 535 robotic kit has been calculated by MATLAB as well as Robo Analyzer. We had calculated the End effector matrix in both software and compare it. We found that the results are similar up to three digit in some elements and up to two digits from decimal in few elements and it was different after three digit from the decimal in end effector matrix.
\end{abstract}

Copyright $@ 2016$ Institute of Advanced Engineering and Science. All rights reserved.

\section{INTRODUCTION}

The kinematic of the manipulator refers to how to calculate a position and orientation of the end effector and to get the desired configuration of the manipulator. Dynamic properties, such as weight, inertia etc., are not considered as part of the kinematics [1]. Kinematic model describes the spatial position of joints and links, and position and orientation of the end-effector [2, 3, 4].The representation of the robot's endeffector position and orientation through the geometries of robots (joint and link parameters) are called Forward Kinematics. Using Forward Kinematics, the mathematical model is developed to compute the position and orientation of end-effector's based on the given Robot joint position. Each Robot joint is considered as revolute joint. The homogenous transformation of end-effector related to the base frame is formulated using Denavit-Hartenberg (D-H) method [5]. A robotic manipulator is designed to perform a task in the 3-D space. The tool or end-effector is to follow a planned trajectory to manipulate objects or carry out the task in the workspace. This requires control of position of each link and joint of the manipulator to control both the position and orientation of the tool. To program the tool motion and joint link motions, a mathematical model of the manipulator is required to refer to all geometrical and/or time-based properties of the motion [6]. This paper adopted a forward kinematics model predicated (DH) analytical scheme for robot arm position placement. The developed model aims at predicting and recovering the end-effecter position of OWI 535 Robot manipulator for different joint variables; finally in the environment of MATLAB, the forward kinematics model is built to take kinematics iteration by using MATLAB. 


\section{ROBOT DESCRIPTION}

OWI- 535 Robot manipulator used in the work is a 4 DOF robot arm manipulator shown in fig. (1). It is a four articulated coordinate robotic manipulator that uses DC motors with worm gear for joint actuators, and its motion are controlled by wired remote. OWI- 535 Robot manipulator has a stationary base, shoulder, elbow and wrist in corresponding with human arm joints, each of these joint has a single DOF. Wrist can move into planes, this making the end-effector move smoothly in terms of object manipulation.

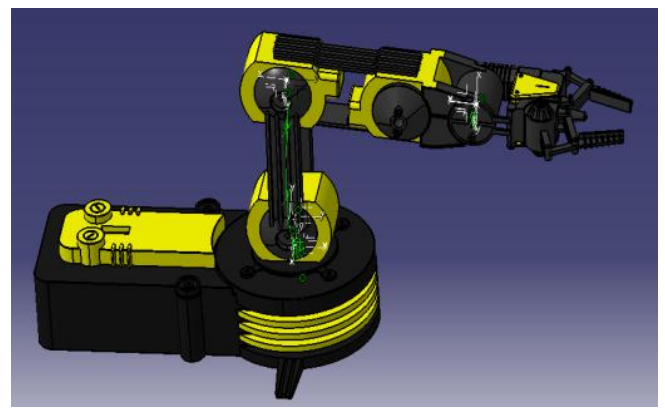

Figure 1. CAD Model of Four axis robotic Kit OWI- 535

OWI-535 is the 4 DOF educational serial manipulators which can be utilize to pick-place \& hold the commodities with in the working volume. All the four joint movements are rotary which make the model of configuration $4 \mathrm{R}$ or R-R-R-R type.

\subsection{Forward kinematics of robotic kit OWI- 535}

In this paper we are using four link robots shown in Figure 3. In order to find relation between first link and last link we fixed the base. This can be obtained from the description of the coordinate transformations between the coordinate frames attached to all the links and forming the overall description in a recursive manner. For this purpose, the position and orientation of the rigid body is useful for obtaining the composition of coordinate transformations between the consecutive frames. As a first step, this method is to be derived to define the relative position and orientation of two successive links. The problem is to define two frames attached to two successive links and make the coordinate transformation between them. It is convenient to set some rules for the definition of the link frames.

The DH parameters corresponding to this 4 DOF OWI- 535 robot manipulator are shown in Table 1. Here $\theta \mathrm{i}$ is the joint angle, bi is joint offset, ai is link length, and $\alpha \mathrm{i}$ is the twist angle. The limits of each of the joint angles have also been given in the table and these limits are also used in the MATLAB programming. The Denavit-Hartenberg (DH) convention and methodology is used to derive its forward kinematics.

We used the above mention set of joint off-set ' $b$ ', joint angle ' $Y$ ', link length ' $a$ ', twist- angle ' $\alpha$ 'only varying the joint angle from minimum value to maximum value with the two intermediate values.

Table 1. D-H Parameters of OWI- 535 robotic kit

\begin{tabular}{lccccc}
\hline $\begin{array}{l}\text { Revolute } \\
\text { Joint }\end{array}$ & $\mathbf{b}(\mathbf{m m})$ & $\begin{array}{c}\mathbf{Y}_{\min } \\
\text { (deg.) }\end{array}$ & $\begin{array}{l}\mathbf{Y}_{\max } \\
(\mathbf{d e g} .)\end{array}$ & $\mathbf{a ~ ( m m )}$ & $\begin{array}{c}\alpha \\
\text { (deg.) }\end{array}$ \\
\hline Joint1 & 0 & $0^{\circ}$ & $270^{\circ}$ & 44 & $90^{\circ}$ \\
Joint2 & 0 & $0^{\circ}$ & $300^{\circ}$ & 91 & $0^{\circ}$ \\
Joint3 & 0 & $0^{\circ}$ & $180^{\circ}$ & 120 & $0^{\circ}$ \\
Joint4 & 0 & $0^{\circ}$ & $120^{\circ}$ & 94 & $0^{\circ}$ \\
\hline
\end{tabular}

As per as the skeleton kinematic figure 3 we can see that the twist angle " $\alpha$ " i.e orientation of zaxis of two joints along $x$ direction (we can say that angle between z-axis) of owi-535model is $90^{\circ}, 0^{\circ}, 0^{\circ}$, $0^{\circ}$ respectively for the joint 1 , joint 2 , joint 3 , joint 4 .

The working links may only alter the joint angle so we select joint angles for the different joints as a variable parameter to perform the analysis to obtain the transformation matrix. 


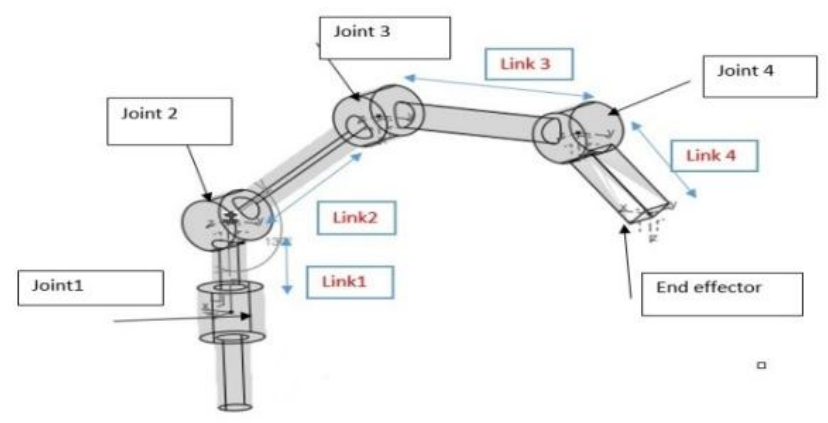

Figure 3. Kinematic schematic diagram of the robotic kit OWI- 535

\subsection{Transformation matrix}

After establishing (D-H) coordinate system for each link, a homogeneous transformation matrix can easily be developed considering frame $\{i-1\}$ and frame $\{i\}$ transformation consisting of four basic transformations. There four parameters are respectively joint angle $\theta \mathrm{i}$, link offset bi, link length ai and the twist angle $\alpha \mathrm{i}$, So, the link transformation matrix between coordinate frame i-1 and coordinate frame i.MATLAB code for transformation matrix has been given in appendix.

\section{VERIFICATION OF MATHEMATICAL MODEL USING MATLAB 10.0 PROGRAM WITH ROBO ANALYZER SOFTWARE}

The simulation results as presented are for the forward kinematic analysis of the OWI 535 Robot as modelled using the (D-H) concept. Simulations were conducted using MATLAB coding on an Intel (R) CPU T2080@ 0.99GHz, 1.00GB Memory (RAM), 32bit Operating System. The MATLAB coding was used to do mathematical iterations of the serial link manipulator. The variables $\theta 1, \theta 2, \theta 3$, and $\theta 4$ respectively represent the joint axes 1 through 4 . Kinematics equations from the overall transformation matrix were developed using the MATLAB R 10.0. An code has been developed to generate the forward kinematics equations and calculate the robot Manipulator position and orientation in terms of joint angles and its output is compared with Robot software (which is the simulate program supplied with the robot system) for four sets of joint parameters. The result of end-effecter's position from MATLAB iteration was then compared with experimental result generated from inbuilt Robo Analyzer software. For different keyboard values entered on the Robo Analyzer software, the corresponding joint angles, simulation and experimental positions for the end-effecter are presented.

\subsection{Input sets of $D-H$ values:}

We have link length, off sett and twist angles for the manipulator are fixed so we can vary the joint angle hence these are the different input sets of D-H parameters to MATLAB and Robo Analyzer for different values of joint angle are as follows

Table 3: D-H set1 Parameters of different joints for $\mathrm{Y}_{\min }$

\begin{tabular}{ccccc}
\hline Revolute Joint & $\mathrm{b}(\mathrm{mm})$ & $\mathrm{Y}_{\min }(\operatorname{deg})$. & $\mathrm{a}(\mathrm{mm})$ & $\alpha($ deg. $)$ \\
\hline Joint1 & 0 & $0^{\circ}$ & 44 & $90^{\circ}$ \\
Joint2 & 0 & $0^{\circ}$ & 91 & $0^{\circ}$ \\
Joint3 & 0 & $0^{\circ}$ & 120 & $0^{\circ}$ \\
Joint4 & 0 & $0^{\circ}$ & 94 & $0^{0}$ \\
\hline
\end{tabular}

Table 4: D-H set2 Parameters of different joints for $\mathrm{Y}_{\text {intermediatel }}$

\begin{tabular}{ccccc}
\hline $\begin{array}{c}\text { Revolute } \\
\text { Joint }\end{array}$ & $\mathrm{b}(\mathrm{mm})$ & $\mathrm{Y}_{\min }(\mathrm{deg})$. & $\mathrm{a}(\mathrm{mm})$ & $\alpha($ deg.) \\
\hline Joint1 & 0 & $60^{\circ}$ & 44 & $90^{\circ}$ \\
Joint2 & 0 & $60^{\circ}$ & 91 & $0^{\circ}$ \\
Joint3 & 0 & $60^{\circ}$ & 120 & $0^{\circ}$ \\
Joint4 & 0 & $60^{\circ}$ & 94 & 00 \\
\hline
\end{tabular}


Table 5: D-H set3 Parameters of different joints for $\mathrm{Y}_{\text {intermediate2 }}$

\begin{tabular}{ccccc}
\hline $\begin{array}{c}\text { Revolute } \\
\text { Joint }\end{array}$ & $\mathrm{b}(\mathrm{mm})$ & $\mathrm{Y}_{\min }($ deg. $)$ & $\mathrm{a}(\mathrm{mm})$ & $\alpha($ deg.) \\
\hline Joint1 & 0 & $100^{\circ}$ & 44 & $90^{\circ}$ \\
Joint2 & 0 & $100^{\circ}$ & 91 & $0^{\circ}$ \\
Joint3 & 0 & $80^{\circ}$ & 120 & $0^{\circ}$ \\
Joint4 & 0 & $80^{\circ}$ & 94 & $0^{0}$ \\
\hline
\end{tabular}

Table 6: D-H set4 Parameters of different joints for $Y_{\max }$

\begin{tabular}{ccccc}
$\begin{array}{c}\text { Revolute } \\
\text { Joint }\end{array}$ & $\mathrm{b}(\mathrm{mm})$ & $\mathrm{Y}_{\min }($ deg. $)$ & $\mathrm{a}(\mathrm{mm})$ & $\alpha($ deg.) \\
\hline Joint1 & 0 & $270^{\circ}$ & 44 & $90^{\circ}$ \\
Joint2 & 0 & $300^{\circ}$ & 91 & $0^{\circ}$ \\
Joint3 & 0 & $180^{\circ}$ & 120 & $0^{\circ}$ \\
Joint4 & 0 & $120^{\circ}$ & 94 & $0^{0}$ \\
\hline
\end{tabular}

Putting these above mention sets of values and obtaining results for transformation matrix in MATLAB.

\section{OUTPUT FROM THE SETS OF D-H VALUES}

\subsection{MATLAB Results}

For the set 1 for $Y_{\min }$

$\begin{array}{rrrr}1.0000 & 0 & 0 & 0.3490 \\ 0 & 0 & -1.0000 & 0 \\ 0 & 1.0000 & 0 & 0 \\ 0 & 0 & 0 & 1.0000\end{array}$

For the set $2 \mathrm{Y}_{\text {intermediate } 1}$

$\begin{array}{rrrr}-0.5000 & 0.0000 & 0.8660 & -0.0323 \\ -0.8660 & 0.0000 & -0.5000 & -0.0559 \\ -0.0000 & -1.0000 & 0 & 0.1827 \\ 0 & 0 & 0 & 1.0000\end{array}$

For the set $3 \mathrm{Y}_{\text {intermediate2 }}$

$\begin{array}{rrrr}0.0302 & -0.1710 & 0.9848 & 0.0188 \\ -0.1710 & 0.9698 & 0.1736 & -0.1065 \\ -0.9848 & -0.1736 & 0 & -0.0030 \\ 0 & 0 & 0 & 1.0000\end{array}$

For the set $4 \mathrm{Y}_{\max }$

$\begin{array}{rrrr}0 & 0 & -1.0000 & 0 \\ 0.5000 & -0.8660 & 0 & 0.0175 \\ -0.8660 & -0.5000 & 0 & -0.0563 \\ 0 & 0 & 0 & 1.0000\end{array}$

\subsection{Robo Analyzer Configuration Sets}

For the set $1 \mathrm{Y}_{\min }$ 


\begin{tabular}{l|l|l|l|l|l|l|l|l|}
\hline $\begin{array}{l}\text { Joint } \\
\text { No }\end{array}$ & Joint Type & $\begin{array}{l}\text { Joint Offset } \\
\text { (b) } \mathrm{m}\end{array}$ & $\begin{array}{l}\text { Joint Angle } \\
\text { (theta) deg }\end{array}$ & $\begin{array}{l}\text { Link Length } \\
\text { (a) } \mathrm{m}\end{array}$ & $\begin{array}{l}\text { Twist Angle } \\
\text { (alpha) deg }\end{array}$ & $\begin{array}{l}\text { Initial Value } \\
\text { (JV) deg or } \mathrm{m}\end{array}$ & $\begin{array}{l}\text { Final Value } \\
\text { (JV) deg or } \mathrm{m}\end{array}$ \\
\hline 1 & Revolute & 0 & Variable & 0.044 & 90 & 0 & 0 \\
\hline 2 & Revolute & 0 & Variable & 0.091 & 0 & 0 & 0 \\
\hline 3 & Revolute & 0 & Variable & 0.12 & 0 & 0 & 0 \\
\hline 4 & Revolute & 0 & Variable & 0.094 & 0 & 0 & 0
\end{tabular}

For the set $2 Y_{\text {intermediate } 1}$

\begin{tabular}{l|l|l|l|l|l|l|l|l}
$\begin{array}{l}\text { Joint } \\
\text { No }\end{array}$ & Joint Type & $\begin{array}{c}\text { Joint Offset } \\
\text { (b) } \mathrm{m}\end{array}$ & $\begin{array}{l}\text { Joint Angle } \\
\text { (theta) deg }\end{array}$ & $\begin{array}{l}\text { Link Length } \\
\text { (a) } \mathrm{m}\end{array}$ & $\begin{array}{c}\text { Twist Angle } \\
\text { (alpha) deg }\end{array}$ & $\begin{array}{l}\text { Initial Value } \\
\text { (JV) deg or m }\end{array}$ & $\begin{array}{l}\text { Final Value } \\
\text { (JV) deg or } \mathrm{m}\end{array}$ \\
\hline 1 & Revolute & 0 & Variable & 0.044 & 90 & 0 & 60 \\
\hline 2 & Revolute & 0 & Variable & 0.091 & 0 & 0 & 60 \\
\hline 3 & Revolute & 0 & Variable & 0.12 & 0 & 0 & 60 \\
\hline 4 & Revolute & 0 & Variable & 0.094 & 0 & 0 & 60 \\
\hline
\end{tabular}

For the set $3 \mathrm{Y}_{\text {intermediate2 }}$

\begin{tabular}{|l|l|l|l|l|l|l|l|l|}
$\begin{array}{l}\text { Joint } \\
\text { No }\end{array}$ & Joint Type & $\begin{array}{l}\text { Joint Offset } \\
\text { (b) } \mathrm{m}\end{array}$ & $\begin{array}{l}\text { Joint Angle } \\
\text { theta) deg }\end{array}$ & $\begin{array}{l}\text { Link Length } \\
\text { (a) } \mathrm{m}\end{array}$ & $\begin{array}{l}\text { Twist Angle } \\
\text { (alpha) deg }\end{array}$ & \multicolumn{1}{l}{$\begin{array}{l}\text { Initial Value } \\
\text { (JV) deg or m }\end{array}$} & \multicolumn{2}{l|}{$\begin{array}{l}\text { Final Value } \\
\text { (JV) deg or m }\end{array}$} \\
\hline 1 & Revolute & 0 & Variable & 0.044 & 90 & 0 & 100 \\
\hline 2 & Revolute & 0 & Variable & 0.091 & 0 & 0 & 100 \\
\hline 3 & Revolute & 0 & Variable & 0.12 & 0 & 0 & 80 \\
\hline 4 & Revolute & 0 & Variable & 0.094 & 0 & 0 & 80 \\
\hline
\end{tabular}

For the set $4 \mathrm{Y}_{\max }$

\begin{tabular}{l|l|l|l|l|l|l|l|l|}
$\begin{array}{l}\text { Joint } \\
\text { No }\end{array}$ & Joint Type & $\begin{array}{c}\text { Joint Offset } \\
\text { (b) } \mathrm{m}\end{array}$ & $\begin{array}{c}\text { Joint Angle } \\
\text { (theta) deg }\end{array}$ & $\begin{array}{l}\text { Link Length } \\
\text { (a) } \mathrm{m}\end{array}$ & $\begin{array}{l}\text { Twist Angle } \\
\text { (alpha) deg }\end{array}$ & $\begin{array}{l}\text { Initial Value } \\
\text { (JV) deg or } \mathrm{m}\end{array}$ & $\begin{array}{l}\text { Final Value } \\
\text { (JV) deg or m }\end{array}$ \\
\hline 1 & Revolute & 0 & Variable & 0.044 & 90 & 0 & 270 \\
\hline 2 & Revolute & 0 & Variable & 0.091 & 0 & 0 & 300 \\
\hline 3 & Revolute & 0 & Variable & 0.12 & 0 & 0 & 180 \\
\hline 4 & Revolute & 0 & Variable & 0.094 & 0 & 0 & 120 \\
\hline
\end{tabular}

\subsection{Robo Analyzer Results}

For the set 1 for $\mathrm{Y}_{\min }$

$\left[\begin{array}{llll}1 & 0 & 0 & 0.349 \\ 0 & 0 & -1 & 0 \\ 0 & 1 & 0 & 0 \\ 0 & 0 & 0 & 1\end{array}\right]$

For the set $2 \mathrm{Y}_{\text {intermediate } 1}$

$\left[\begin{array}{llll}-0.5 & 0 & 0.866025 & -0.03225 \\ -0.866025 & 0 & -0.5 & -0.055859 \\ 0 & -1 & 0 & 0.182731 \\ 0 & 0 & 0 & 1\end{array}\right]$

For the set $3 \mathrm{Y}_{\text {intermediate2 }}$

$\left[\begin{array}{llll}0.030154 & -0.17101 & 0.984808 & 0.018776 \\ -0.17101 & 0.969846 & 0.173648 & -0.106482 \\ -0.984808 & -0.173648 & 0 & -0.002954 \\ 0 & 0 & 0 & 1\end{array}\right]$




$\left[\begin{array}{llll}\text { For the set } 4 \mathrm{Y}_{\max } \\ 0 & 0 & -1 & 0 \\ 0.5 & -0.866025 & 0 & 0.0175 \\ -0.866025 & -0.5 & 0 & -0.056292 \\ 0 & 0 & 0 & 1\end{array}\right]$

\section{CONCLUSION \& DISCUSSION}

The output of the transformation matrices from the varied D-H parameter joint angles for the educational OWI- 235 manipulator for the result of MATLAB had come out to be same as for result transformation matrices from the Robo-analyzer .But point to be noted that the MATLAB results are same with Robo Analyzer results up to only two places after decimal the third digit after decimal varied in some elements of the MATLAB matrices obtained \& the MATLAB gives the result components of the transformation matrices up to four places after decimal but as for same configuration of manipulator Roboanalyzer gives result and matrix elements has digital up to six places from decimal in transformation matrices. That means if researcher had D-H parameters values and need to evaluate the transformation matrix they should be prefer Robo-analyzer rather than the MATLAB for accuracy point of view.

As the above conclusion states that there is variation starts from the third place after the decimal in the above used software's result values, so for precision work there is need to define the correct value form the third place of decimal obtained from different software's. We need another software or another coding platform to find more accurate results.

\section{APPENDIX}

MATLAB PROGRAM

For estimating the transformation matrix the general code for a $4 \mathrm{R}$ configuration manipulator is

syms bl thetal al alphal:

$\mathrm{Qb} 1=\left[\begin{array}{llllllllllllll}1 & 0 & 0 & 0 ; 0 & 1 & 0 & 0 ; 0 & 0 & 1 & \mathrm{~b} 1 ; 0 & 0 & 0 & 1\end{array}\right] ;$

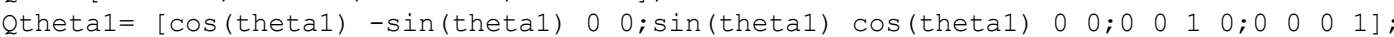
$\mathrm{Q} a 1=\left[\begin{array}{llllllllllllll}1 & 0 & 0 & a 1 ; 0 & 1 & 0 & 0 ; 0 & 0 & 1 & 0 ; 0 & 0 & 0 & 1\end{array}\right]$;

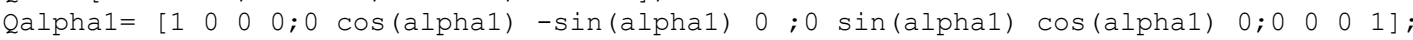
Qdh1 $=\mathrm{Qb} 1 *$ Qtheta1*Qa1*Qalpha1

syms b2 theta2 a2 alpha2;

$\mathrm{Qb} 2=\left[\begin{array}{lllllllllllllll}1 & 0 & 0 & 0 ; 0 & 1 & 0 & 0 ; 0 & 0 & 1 & \mathrm{~b} 2 ; 0 & 0 & 0 & 1\end{array}\right]$

Qtheta2 $=[\cos ($ theta2) $-\sin ($ theta 2$) \quad 0 \quad 0 ; \sin ($ theta2) $\cos ($ theta2) $0 \quad 0 ; 0 \quad 0 \quad 10 ; 00$ o 1 ; ;

$\mathrm{Qa} 2=\left[\begin{array}{lllllllllllll}1 & 0 & 0 & \mathrm{a} 2 ; 0 & 1 & 0 & 0 ; 0 & 0 & 1 & 0 ; 0 & 0 & 0 & 1\end{array}\right]$;

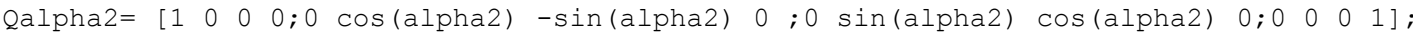
$\mathrm{Qdh} 2=\mathrm{Qb} 2 * \mathrm{Q}$ theta $2 * \mathrm{Qa} 2 * \mathrm{Qalpha} 2$

syms b3 theta3 a3 alpha3;

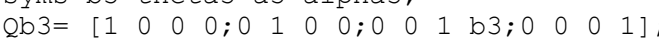

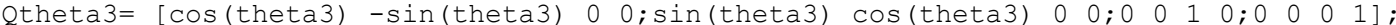



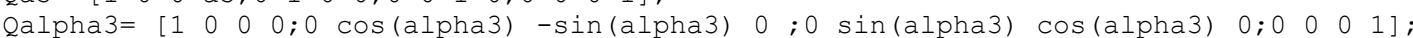
Qdh3 $=$ Qb3*Qtheta3*Qa3*Qalpha3

syms b4 theta4 a4 alpha4;

$\mathrm{Qb} 4=\left[\begin{array}{llllllllllllll}1 & 0 & 0 & 0 ; 0 & 1 & 0 & 0 ; 0 & 0 & 1 & \mathrm{~b} 4 ; 0 & 0 & 0 & 1\end{array}\right] ;$

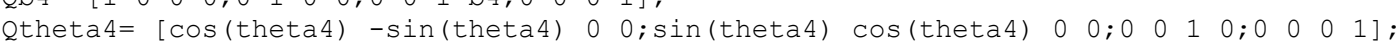

Qa4 $=\left[\begin{array}{lllllllllllllll}1 & 0 & 0 & a 4 ; 0 & 1 & 0 & 0 ; 0 & 0 & 1 & 0 ; 0 & 0 & 0 & 1\end{array}\right]$.

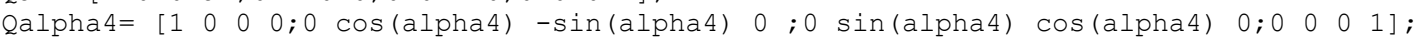

Qdh4 $=\mathrm{Qb} 4 *$ Qtheta $4 * \mathrm{Qa} 4 * \mathrm{Qalpha} 4$

Qdhdof $4=Q \operatorname{dh} 1 * Q \operatorname{dh} 2 * Q \operatorname{dh} 3 * Q d h 4$

\section{REFERENCES}

[1] Mark W. Spong, "Robot Modeling and Control", 1st Edition, John Wiley \& Sons, 2005.

[2] Mittal R.K. \& Nagrath I.J, "Robotics \& Control", First Edition, Tata McGraw-Hill Publishing Co. Ltd., pp 70107,2006

[3] Niku Saeed B, "Introduction to Robotics - Analysis, Systems \& Applications", First Edition, Pearson Education Pvt. Ltd, 2003.

[4] Schiling Robert J, "Fundamentals of Robotics", Prentice-Hall of India Pvt. Lid, pp 25-76, 2009.

[5] John J.Craig," Introduction to Robotics". 2nd ed. Pearson Education International, 2005.

[6] Corke,P.I., "A Robotics Toolbox for MATLAB ", Ninth release, Springer Publishing Co, September 2011. 


\section{BIOGRAPHIES OF AUTHOR}

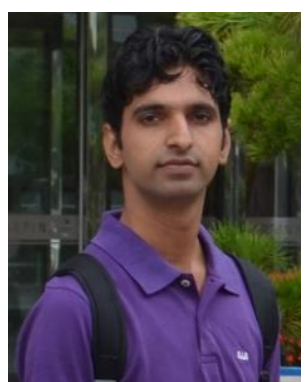

Bhivraj Suthar, I had completed B.E. in Electrical Engineering and post graduated in Energy and Environment Management from Indian Institute of Technology Delhi, India. I have more than 4 years' experience in robotics, Mechatronics, Automation, Control system design of manipulator, Wearable robot, Rehabilitation, Human machine interface, Tele-operation of Industrial robot. I worked as a project associate at IIT Delhi in the area of renewable energy, Micro hydro system design for one year. I also worked as a Junior Research Fellow project titled" Tele operation of Industrial robot" that was joint project of BARC and IIT Delhi. I have one journal paper, nine conference papers in National and International conferences, and four patents. I also got GYTI Award- 2015 at Rastriapati Bhawan New Delhi, India and short listed in top 10 good projects for "IIT Delhi 89 Class of Innovation Award-2015 and Best Research paper award in An International Conference \& Exhibition on Cutting Edge Technological Challenges in Mechanical Engineering at Noida Institute of Engineering \& Technology, Greater Noida, INDIA. 